\title{
Examining an \\ Engineer's Design Studio
}

\section{INTRODUCTION}

To begin this investigation, one asks, 'What is an Engineer's Design Studio?' This paper examines the work and statements of three groups in an attempt to answer this question and define their significance. It must be acknowledged that the term 'Design Studio' is not a label chosen by all of these firms, but one suggested here to encapsulate their work.

An Engineer's Design Studio is a group of engineers engaging in building design. In fact, they are small specialist groups that seek to contribute to the design by challenging the existing assumptions in the design process. By asking bigger questions about a project than their discipline normally allows, a differing viewpoint emerges. These groups use engineering to articulate architectural visions. Again, not necessarily visions of the architect, for which they consult, but visions for the project that they are supporting. The difference is that engineering can be used in the creation of the ideas behind a project and not just in the articulation of the project. Additionally, the groups seek innovation through the use and growth of digital technology.
Design studios within engineering firms in the construction industry are not common. Their existence has much to do with the changes occurring in this digital age. Digital technology not only influences architectural practice, it also reaches into the pedagogy of architectural education. By using the Engineer's Design Studio as an example, one can see how the engineer's aims can be applied to the benefit of current architectural education practices.

\section{Exploring the Groups}

The first of the three groups being examined is Buro Happold's SMART Structural Solutions which was founded in 2002. Their brief as a team is to respond to the architectural challenges of current practice created by complex geometries which explore the boundaries of what can be built. ${ }^{1}$ One of the ways they address these challenges is through tool-making. SMART Structural Solutions capability statement describes this portion of their work as developing, "new technology to enable us to deliver original, innovative and efficient design solutions." ${ }^{2}$ Indeed, they have created tools for optimization, form-finding, and fabric analysis. These programs are sophisticated and have 
been created with a wide scope so that they can be used on multiple projects. As engineers, mathematicians, and programmers, they work not only to derive a structural system that will support fanciful forms, but also to ensure that the engineering is smart, rationalized and buildable. $^{3}$

A project like the Qatar Convention Centre in Doha, with Arata Isozaki, which used optimization and digital fabrication, demonstrates how SMART Solutions have used their skills to realize a project. The $250 \mathrm{~m}$ long curved steel structure of the convention center required, “...resolving the geometry and the structure inside to make sure it will keep its' organic form while being structurally efficient and buildable." ${ }^{\prime 4}$ The construction of the trunk required over a thousand panel pieces. The process of analyzing, cutting, identifying, and forming of the plates was made possible by the digital fabrication skills of the SMART Structural Solutions group.

Arup's Advanced Geometry Unit (AGU), also founded in 2002, is the second of these groups of engineers. However, the Arup team was not composed solely of engineers. It included people trained in science, math, art, and architecture. Using higher level mathematics and advanced computer analysis, this group sought to question organizational systems for building structures, the assumptions that were made in establishing systems, and the analysis of these systems. An example which illustrates the critical exploration conducted by the group is their investigation into "Nonlinear Soap-Film." ${ }^{5}$ Soap bubbles have been long used as a physical modeling technique and for exploration into complex surfaces. AGU asked if soap film was the appropriate modeling technique for fabric structures. They then thought otherwise as the team described soap bubble modeling, "It is a simple model that produces a surface that has uniform tension in all directions. However, membrane structures are not built from soap films so these rules are arbitrary in their own right..." 6
With today's technology, woven fabric can be modeled more accurately with computer software and the manufacturing of a material can explore using different strand strengths at different locations. AGU asked why, then, are we using analog tools to build in an era where digital tools have greatly expanded our capacity? And, if analytical tools do not exist, why not create them? AGU pursued exploration of fabrics, model of fabrics, and fabric construction through several projects including: Anish Kapoor's swooping Marsyas Sculpture at the Tate Modern in 2002; the Alishan Bridge with its woven structural system (2004); and the UPenn Weave Bridge which explores threedimensional weaving (2009.)

Another of the Advanced Geometry Group's aspirations was to challenge who can author a project. They saw their engineers not only as the experts who made some of these projects possible, but also as the engineers who brought ideas to the project that impacted its formation. Due to the complexity of the projects they undertook, they were frequently invited on a project as collaborators in the initial stages of a project. ${ }^{7}$ AGU's role allowed an open dialogue on the project and these relationships demonstrated that changes are occurring. This challenge is not just about seeking credit for their work with an acknowledgement of a greater role in the design process. Rather, it also reflects an understanding that the architecture can be made better by these partnerships. As one of the founders of AGU, Charles Walker, remarked, "I believe things will move in the direction of partnering and networking over the longer term. This could allow much greater creativity in design and construction...." ${ }^{8}$ This creativity occurs, as the AGU argument leads, only when engineers are allowed to collaborate.

The third group being examined here is Skidmore, Owings, and Merrill's BlackBox Studio. Founded in 2007 and based in SOM's Chicago office, BlackBox Studio is a small group of architects with training in Product Architecture and Engineering from the Stevens Institute of Tech- 
nology School of Engineering \& Science. The program, where the team members trained, as the Steven Institute describes, “...blends architecture, engineering, and industrial design to find elegant and effective solutions for building and construction challenges." ${ }^{\prime 9}$ So while the group members are self-identified architects, their training is broader and embraces engineering. Given this background, the team seeks to "...bridge...the worlds of design and technology," ${ }^{10}$ as group leader Keith Besserud states. They do this through advanced computer skills, rule-based or parametric design, and optimization. Here again, is a group embracing and creating digital tools to explore architectural projects.

Their interest in technology, however, is not limited to computer technology; it also includes the technology involved in forming a building. One of the explicit missions of BlackBox Studio is to "...engage in all stages of the design process across all service disciplines." ${ }^{11}$ This view allows them to include various discipline participation for meaningful input in earlier stages of design. Fields like energy, daylighting, or structures can influence a project and contribute to its formation at the most crucial stages.

Another hallmark of BlackBox's work is their ability to derive multiple solutions quickly. Through multiple iterations a number of solutions can be found to an open-ended problem. For a project in Moscow titled Plot 16, BlackBox studied the site, the curtain walls, and natural light, to give the architects on the project a set of 20 solutions from which to choose. ${ }^{12}$ The set of solutions identified met predetermined performance criteria along with architectural requirements. ${ }^{13}$ The BlackBox Studio uses their skills to bring together different strengths of the firm to create unique and meaningful solutions. And, through their studies and project work, the group seeks to identify and explore new frontiers of conceptual thought and innovation. ${ }^{14}$

The question could be raised as to why this group of architects is included with the engineering groups. One answer is that BlackBox seeks to develop projects by engaging engineering principles in the initial phases. A structural or energy study can be used to derive several of the iterations used to form a building. Thus, choices made about form become smarter and more justified with the use of optimization and engineering. Another reason is that the group's work naturally challenges the idea of only the architect being able to develop the vision of the project. "By casting a broader net, BlackBox and the technologies they investigate paradoxically draw project stakeholders together, blurring traditional distinctions between clients, architects, structural engineers, mechanical engineers, and technical specialists." ${ }^{15}$

\section{Commonalities}

The firms, studied here, are well-known and perhaps, the names of their groups are familiar. However, one can argue, that when studied as a collection of groups, they can now be examined as an indicator of change that is occurring within practice. Project development along with the way architects and engineers work together is being re-examined.

These Design Studios are small groups of specialists, four to ten people. Each group is a selfidentified, named, and marketed team within a larger corporate structure. They are comprised of individuals with multidisciplinary backgrounds in fields such as art, computer science, and architecture, in addition to engineering. The firms, in which they exist, have histories of multidisciplinary practices - either a combination of engineering disciplines or a combination of architecture and engineering. The commitment of the firms to a multidisciplinary framework indicates that they value input from team members with differing, or discipline based, priorities. The formation of these specialized teams allows the larger firm to further focus on multidisciplinary design and within each firm there is recognition that there is value in this exploration. 
It is significant that these groups exist within much larger firms, because, collectively, these large firms have hundreds of years of experience in multiple areas. While the size of the specialist team is minimal, their access to knowledge is extremely deep. These teams excel by networking within a much larger organization. As they find themselves creating solutions, challenges may be uncovered and they can connect with someone in their firm to find an answer. At the same time, their very existence encourages internal networking and collaboration. From these more complicated projects, skills are identified, research is developed, and computer programs created. This knowledge is fed back into the firm and shared.

These design teams were each founded with the intent of being an applied research unit. They attempt to find solutions to unique problems and to use process along with the final solution to provide a depth of experience. They build tools that can be applied to future projects and use digital technology to advance both architectural and structural design. The groups study the complex geometry of the architectural form and the supporting systems required.

The studio format allows for the exchange of ideas within a group of like-minded individuals and provides a creative environment that encourages exploration. Each individual brings a range of talents and an understanding that every system is open to examination and that new ways forward are possible. This passion to find a solution by whatever means allows for an open and free exchange of ideas without the limits of the traditional A/E relationship.

The primary tools of these groups are models, both digital and physical. They use scripting, simulation tools, and analysis tools to find a single solution and/or many solutions. They author the framework or sets of rules that allow the computer to seek these solutions. These teams write programs to interface with existing ones, graphically represent results, or to analyze specific inquiries. Models are constructed and refined using these new tools. The building can be optimized in order to find the best engineered solution. Structure can be united with the architecture, rather than the façade applied to a traditional structure. The form can be molded to provide the best shape for the structural performance. As BlackBox describes their work, though it applies to the other groups, it is "rational form-making."16

\section{Observations}

The very existence of these groups is recognition that building forms are becoming more complex. Architects are embracing digital design technologies and their imagination is pushing the realm of what is possible. Because of their training in analytical methods, mathematics, and materials, architects are finding that engineers are good partners to explore these types of buildings. The forms being developed require a higher level of analysis and the more specialized skills that these engineers have in order to ensure that the project can be built. The specialist groups discussed here have a familiarity with non-orthogonal forms and are able to jump into this type of project quickly.

As these studios create the organizational structures for buildings, they are, as a consequence, simultaneously questioning the traditional architect/consultant relationship. Within these teams, solutions are found by everyone working interlaced together. The idea of authorship is greatly diminished. It is the combined strength of the team that finds the solutions. The composition of the team must be multi-faceted to succeed. As Charles Walker of AGU stated, "There is less concern with professional demarcation and more emphasis on the creative functioning of a network of contributors." ${ }^{17}$ Engineers, rather than just providing sizes for floor support, are asking questions such as how can the form and the structure be integrated? Or, what are the rules governing a project? And, why is the form the way it is? Questions that once were solely in the purview of the architect are now being asked by these 
design studios. How this questioning occurs, though, is very much dependent on the philosophy of the individual group.

Using each of the firms' own statements, one can see that they vary in their level of aspirations. SMART Structural Solutions seeks to fill its role as consultant by being able to realize "...some of the most complicated concepts in modern architecture." ${ }^{18}$ Their manifestation of a project is accomplished by using their skills in the highest form of the craft and by focusing on the central engineering principles of structural and material efficiency in conjunction with constructability. The Advanced Geometry Unit's stated mandate was to "...explore new organizational strategies..." beyond post and beam in new and "...irreducible complexities..."19 Additionally, they very forthrightly insist, "As engineers we, too, wish to create a contemporaneous design and we see our discipline as equally cultural." ${ }^{20}$ Thus, while SMART Structural Solutions sees a change in architectural practice and has a need to refine their skills to address the architectural demands, they do not explicitly call for a redefinition of their role. $A G U$, on the other hand, claims that the traditional roles are changing and they wanted to have a significant influence on this change. The BlackBox Confederation, a group of multi-disciplinary architects, seeks to define its role in the "evolving digital design paradigm" and to unite the worlds of design, data and technology. ${ }^{21}$ Their work seeks to challenge every role in the project. They ask how architects can rethink their design processes, how can engineering be smarter, and how engineers can contribute the form of the building.

If the ideas behind these groups are examined, what can be extracted from an analysis of them? As architectural challenges require more technical solutions, more specific skills will be needed and the demand for technical specialists will rise. At the same time, these specialists can only exist if there are networks that can access these skills. Project teams, while already global, will become more interdisciplinary and more informal. The role of lead designer will be shared by teams because the solution will only be found through the correct assembly of committed specialists. Perhaps one emerging model will be that while the architect will continue to interpret the client's needs and provide a concept for the project, their role may now be expanded to define a group of rules and to incorporate many visions developed by a design team which includes non-architects. Thus, the architect may be intellectually guiding a project rather than governing it.

\section{Architectural Education in the Digital Age}

Just as an examination of the Engineer's Design studio yielded a revisiting of traditional roles, questions are being asked today about the traditional forms of higher education. The typical university student has no memory of a world without the Internet. Today's third-year architecture student was born in 1990 which was one year before the World Wide Web was launched. The student of today arrives in the classroom with innate technical know-how, the ability to multi-task, and a background of self-learning from a non-hierarchical network. A study sponsored by the MacArthur Foundation even suggests that students at an early age have experience to coding through customizing games such as Pokémon. ${ }^{22}$ Students exist in a time when knowledge is developing at a rapid pace, yet as another study suggests, Ichabod Crane, Washington Irving's legendary schoolteacher from The Legend of Sleepy Hollow (1820) would be able to find his place in almost any classroom today. ${ }^{23}$ Is it any wonder that the "Sage on the Stage" format for teaching is being questioned? ${ }^{24}$

Many institutions, of course, are exploring what being in the beginning of the Digital Age means for education for both teaching and attracting students. In a recent Economist Intelligence Unit study, "63\% of survey respondents....say that technological innovation will have a major impact on teaching methodologies over the next five years." ${ }^{25}$ When asked about the avail- 
ability of new technologies, $73 \%$ of the same respondents thought it would be very important to a student when choosing a university to attend. ${ }^{26}$ For getting the best students and keeping them engaged, technology has a very important role.

A few conclusions about how we teach and the way students want to learn may be derived from their use of the internet. Because of what is found online, students are accustomed to learning through a variety of media: text, charts and other graphical information, music, audio segments, and video. They naturally understand that "...learning is increasingly facilitated by exploration, interaction, and problem-solving,..."27 or phrased in another way, they anticipate learning to be facilitated through participative learning opportunities. Additionally, students are open and available to networking, interdisciplinary work, and expect learning to occur with as few boundaries as possible - even that of the classroom itself.

What does this mean for educators? Educators will be expected to design learning experiences, not just lectures. Also, due to the ease of access to information, the hierarchical role of the professor/student relationship is not as respected as much as it was in earlier generations. So, while students expect more from their professors, they do not necessarily expect learning to come only from qualified, credentialed professionals. Lastly, the idea of the network can be seen as underlying the emerging models of education. Networks between institutions, research groups, and disciplines are now expanding and are expected to become more rooted in the university structure. As an educator, one must ask, how can the idea of network be used in their class?

In architectural education, design studios are full of computers, complex geometric designs, and teams. The studio is certainly a participative learning environment. But, does this mean that architectural education is at the cutting edge? There are great strides being taken to examine and advance what architectural education is today with the digital tools available. For example, architecture schools may have parametric design studios, coding seminars, and digital fabrication labs, but, there are still lessons to be learned.

\section{Applications to Architectural Education}

Like the Engineering Design Groups, educational innovations can be found in examining the assumptions of an analog world in which many of today's educators were educated. The first of these assumptions to be questioned is that the students want to be educated in the same manner as their instructors. While large amounts of material need to be passed from one generation of architect to the next, the method in which this occurs needs to challenge today's students. How do educators fully embrace the digital technology that students today live and breathe? How do all the components of an architectural education get taught in participatory methods?

One question educators can ask is, 'What are the skills needed in the Twenty-First Century Architect?' Every educator will recognize the need for critical analysis among their students. While this is not a new requirement, it is one that may need emphasizing. In a world full of information and sources, students must be able to sort and appropriately apply this information. At the same time, the programs that architectural students are using are becoming more complex with better interfaces. Students can build more complex models and yet, understand less about how it is accomplished. As guides, instructors can pull back the curtain and expose the assumptions of the program, and ask the students to think critically about them. Simple exercises might include understanding the actual dimension of a brick, how a wall is actually constructed, or the dimensions of theater seating. A more challenging exercise for both the student and the instructor could involve students writing their own tools or interfaces. Groups like AGU and BlackBox ques- 


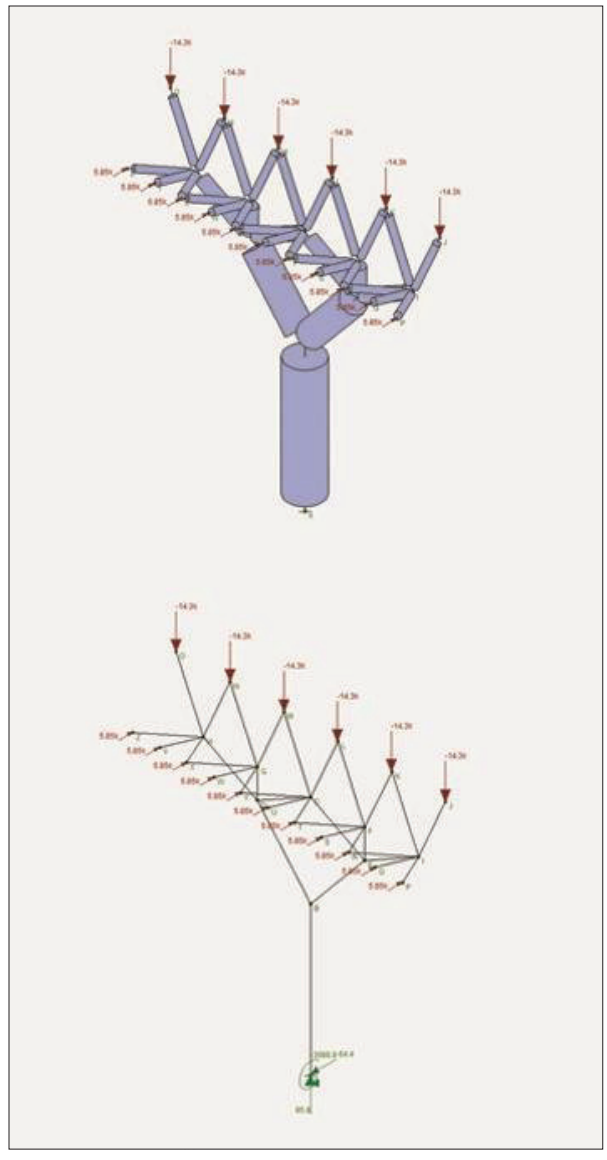

Figure 1: Analysis of a structural support by Cameron Laabs, student at the University of Illinois at UrbanaChampaign.

tioned assumptions of design, of analysis, of form and of the programs used to create solutions. By designing their own tools, students can begin to understand the wealth of information embedded in the programs they use and the decisions that are unwittingly being made for them.

Another area to explore is the use of various forms of media to teach architecture. Architecture itself is multi-media, but the tools used to teach it could expand to include more visual tools. The BlackBox Studio found that it was important to be able to represent the results of their studies graphically. By using graphics, architects within their firm were able to gain an intuitive understanding of how their building

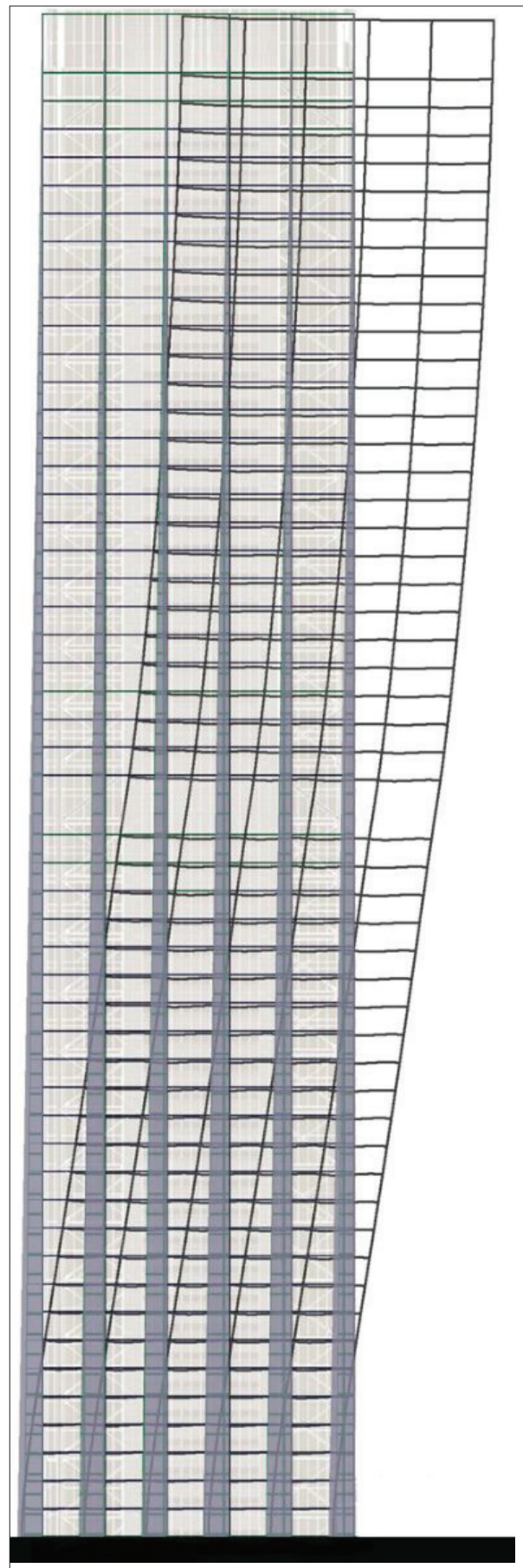

Figure 2: Analysis of load and deflection by Zachary Helfer, student at the University of Illinois at UrbanaChampaign. 
was performing much more quickly than waiting for years of experience to teach them.28 As Keith Besserud states, "we're increasing our knowledge bank and the designers develop a better understanding of 'form to performance.'"29

Applying this multi-media approach to the classroom, the way load and load paths are taught can be re-examined. Students' intuitive understanding of load path can be strengthened by using multiple forms of representation. For example, students can use a simple structural analysis program to gain this understanding as most programs are able to display results in diagrams. After learning how to calculate loads in a truss, for example, what if the students then modeled it? And, then modified the model? Certainly, this will allow students to have the ability to experiment and gain an intuitive understanding. Again, BlackBox found that architects were eager to use other disciplines programs to get this understanding. ${ }^{30}$ Similarly students are coming to the design studio ready to engage in multiple tools. Figures 1 and 2 illustrate student work which examines structural behavior through an analysis program.

The work of Arup, Buro Happold, and SOM to find new innovations and new modes of thinking happens in part because their work is interdisciplinary. With the teams' computational skills, engineering skills, and the ability to move over traditional barriers, new approaches are being found. Today's architectural students are expecting their world to have this same level of collaboration and freshness. New methods of teaching building technology can engage the architecture student in a way that does not put up barriers between architectural and technology. These barriers do not yet exist for them, and now, in the era of collaboration, is not the time to erect them. Technology can and should move from the boring lecture hall to participatory learning opportunities. Can the studio provide those opportunities? Can architecture schools pair up with engineering schools who are also seeking collaborations?31 While it is difficult to create self-directed learning on the subject of structures, mechanical, and energy systems, the learning experiences may be longer lasting if successful.

\section{CONCLUSION}

This paper started with the proposition that there is an engagement by engineers to impact the traditional design processes in a few small, but influential teams. The groups or teams identified are unique entities that are using advanced computing to answer some of the questions that the use of digital technology raises within the field. Whether consciously aware or not, some of the same questions are being raised within the framework of our institutions by educators and more pressingly the students. The Engineer's Design Studios present some new ideas that challenge some of the underlying assumptions in practice today. Architectural educators seeking a way forward can look to these small teams by asking some of these same questions and using their ideas to further technology education within Architecture. While only a few ideas were mentioned, many new ideas can be found. It is a time of great change, so why do we not take this opportunity to invigorate and challenge tradition in architectural education.

\section{ENDNOTES}

1. Buro Happold. SMART Structural Solutions, Capability Statement. 2011: 5.

2. Ibid.

3. Ibid. Here they speak of a four step integrated approach which takes something, 'from geometry processing, through rationalization, structural optimality and construction scheduling.'

4. Smith, Susan. "Engineering Sidra Trees." Architecture Week February 27, 2008: T1.1. Statement by Dr. Shrikant Sharma.

5. Bosia, Daniel, Martin Self, and Tristan Simmonds. "Woven Surface and Form." Architectural Design 76:6 (Nov/Dec 2006): 84.

6. Ibid, 85 .

7. Tsukui, Noriko. Cecil Balmond, Architecture and Urbanism Special Issue. Japan: A + U Publishing Co., 2006. 
8. Emergence \& Design Group. "Engineering Design: Working with Advanced Geometries." Architectural Design 74: 3 (May/June 2004): 71. While Walker goes on to mention partnering with 'outside' fields, the argument can be made about architecture and engineering alone.

9. Stevens Institute of Technology. "Product Architecture \& Engineering Master's Degree." Accessed June 8, 2011. http://www.stevens.edu/ses/graduate/product-architecture-engineering-grad.html.

10. Brown, Lara. "Thinking Inside the Box." Chicago Architect (Jan/Feb 2010): 45.

11. Skidmore, Owings, and Merrill. "BlackBox Studio." Accessed June 8, 2011. http://www.som.com/content. cfm/services_blackbox

12. Skidmore, Owings, and Merrill. "Inside the BlackBox: SOM's Technological Trajectory." Accessed June 8, 2011. http://www.som.com/content.cfm/blackbox_ technological_trajectory.

13. Ibid

14. Skidmore, Owings, and Merrill. "BlackBox Studio." Accessed June 8, 2011. http://www.som.com/content. cfm/services_blackbox

15. Skidmore, Owings, and Merrill. "Inside the BlackBox: SOM's Technological Trajectory." Accessed June 8, 2011. http://www.som.com/content.cfm/blackbox_ technological_trajectory.

16. Ibid.

17. Emergence \& Design Group. "Engineering Design: Working with Advanced Geometries." Architectural Design 74: 3 (May/June 2004): 71.

18. Buro Happold. SMART Structural Solutions, Capability Statement. 2011:5.

19. Tsukui, Noriko. Cecil Balmond, Architecture and Urbanism Special Issue. Japan: A + U Publishing Co., 2006.

20. Emergence \& Design Group. "Engineering Design: Working with Advanced Geometries." Architectural Design 74: 3 (May/June 2004): 67.

21. Skidmore, Owings, and Merrill. "The BlackBox Confederation." Accessed June 8, 2011. http://www.som. com/content.cfm/blackbox_technological_trajectory_12.

22. Davidson, Cathy N. and David Theo Coldberg. The Future of Learning Institutions in a Digital Age. Cambridge: MIT Press, 2009.

23. Ibid.

24. Frey, Thomas. "The Future of Education." Accessed June 13, 2011. http://www.futuristspeaker. com/2007/03/the-future-of-education/.

25. Economist Intelligence Unit. "The Future of Higher Education: How technology will shape learning." The Economist Intelligence Unit (2008):5.
26. Ibid, 17.

27. Council of Australian University Directors of Information Technology et al. The Future of Higher Education: Beyond the Campus. EDUCAUSE, 2010:2.

28. Interview with Keith Besserud at SOM, Chicago, June 3, 2011.

29. Brown, Lara. "Thinking Inside the Box." Chicago Architect (Jan/Feb 2010): 45-46.

30. Interview with Keith Besserud at SOM, Chicago, June 3, 2011.

31. Committee on the Engineer of 2020, Phase II, Committee on Engineering Education, National Academy of Engineering. Educating the Engineer of 2020. National Academies Press, 2005. 